\title{
Pathogenesis of Glomerulonephritis: from Chickens to Humans
}

\author{
William G. Couser \\ Woodinville, Wash., USA
}

Let me say again what I said last night, thank you so much, Mark, for putting this whole thing together. As Ron Falk just said, this has been somewhat of a Gordon conference on the current status of research in this area. We have heard some presentations today that are going to be seminal papers when they are published, and we are hearing them before they come out. So this is an event that truly lives up to the scientific standards of Kline Bolton and the Bolton years at UVA, and it is a great privilege to be part of it.

When Mark first contacted me about this and said, 'What do you want to talk about?' I said, 'I think somebody needs to tell the Bolton story: somebody needs to tell how he got from where he started to where he is now.' I think that story is a compelling narrative from the perspective of almost anybody, a student, a young investigator, or even one of Kline's colleagues who can look at it as a parallel track and admire it. So, I would like to review glomerulonephritis as Kline has contributed to it, going from the chicken and the mouse to man. So Mark has actually allowed me to use that title: Pathogenesis of Glomerulonephritis: from Chickens to Humans.

Nobody has shown this picture of the house staff and faculty of the Harvard Medical Service at the old Boston City Hospital (fig. 1). It takes us back to the first time (1970) that Kline and I were in the same place. I am sitting up there looking pretty much the same as I do now! Kline Bolton is here. You can appreciate that Kline is

\section{KARGER}

Fax +4161306 1234 E-Mail karger@karger.ch www.karger.com (c) 2009 S. Karger AG, Basel

$1660-2137 / 09 / 1121-0017 \$ 26.00 / 0$

Accessible online at:

www.karger.com/nep asleep, but I think he explained that by saying his senior resident (myself) harassed him all night and did not let him get much sleep! And the father of us all is sitting up there: Ed Lewis, of course, hasn't changed at all either. That was the origin of the group of three in which Kline and I began our subsequent careers in glomerular disease. We all began the trip that brings us together here today at Boston City Hospital in 1970, where I first met Ed, and Kline later joined the two of us. But from my own perspective - and I think because it is my own perspective, it becomes in part Kline's perspective - the story actually goes back another 4 years to a patient. If you are in the physician scientist world, you find that many careerdetermining stories do go back to patients. We rarely start with interest in genes and molecules; we usually start with an interest in a patient, and I started my research career because of a patient. A patient walked into the University of California in San Francisco in 1966 with a history of coughing up blood, feeling very weak, becoming anemic and developing early renal failure with a very active urine sediment that had red cells, casts and other abnormalities. When that patient was admitted to the hospital, I was assigned as his intern, and a kidney biopsy was done. The biopsy revealed crescents in glomeruli, which have been central to many of the talks we have heard this morning and are central to Kline's career (fig. 2).

Relevant to this story is that this biopsy was the first one ever examined by immunofluorescence microscopy

William G. Couser, MD

16050 169th Avenue NE

Woodinville, WA 98072 (USA)

Tel. +1 206890 4583, Fax +1 425488 5489, E-Mail wgc@u.washington.edu 


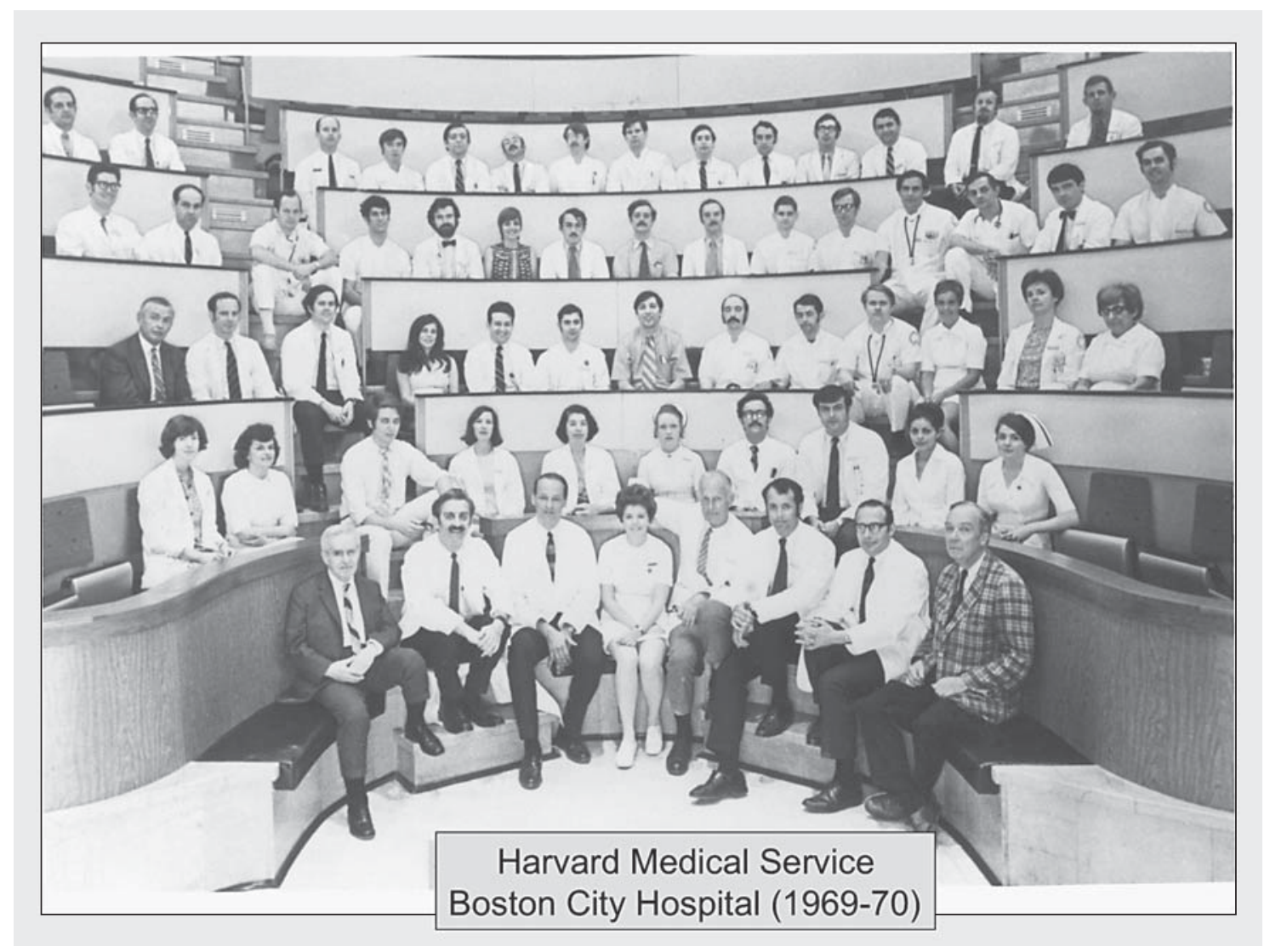

Fig. 1. Harvard Medical Service, Boston City Hospital (1969-1970). The photo shows together for the first time Ed Lewis (top row, left), W. Couser (top row, 3rd from left) as a medical resident, and W. Kline Bolton (3rd row, 6th from right) as an intern. In the 1st row are also shown two eminent Harvard professors, Max Finland (left) and Jim Jandl (3rd from left).

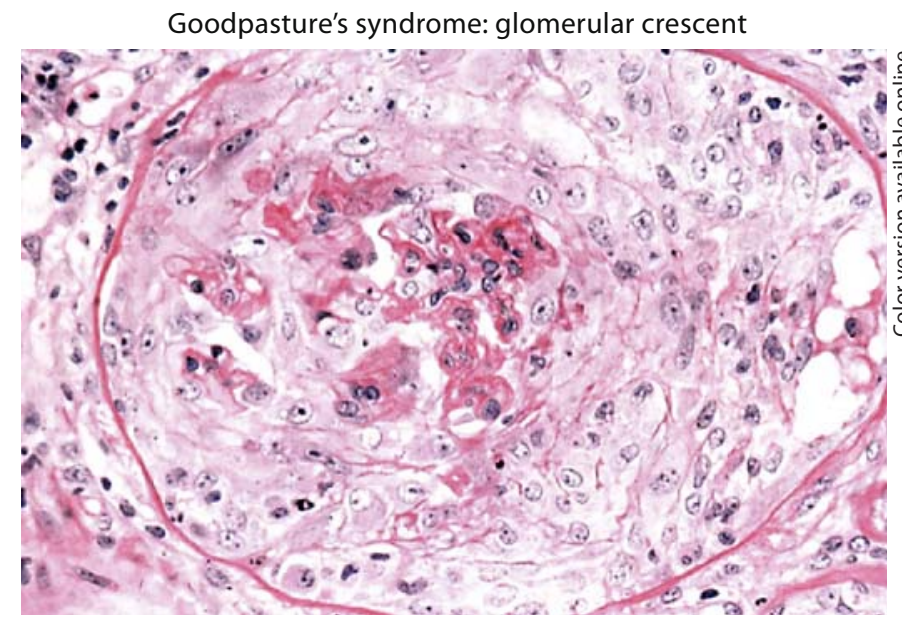

Fig. 2. Glomerular crescent from a patient with a history of hemoptysis, weakness, anemia, and renal failure, with an active urinary sediment. at the University of California in San Francisco. We all went down to the pathology lab and looked through a microscope like the one that Kline was shown looking through earlier, and what we saw was the linear pattern of IgG. Although the paper by Benjamin Sturgill from University of Virginia had been published about a year before that, at that point in time nobody had any idea what this pattern meant. They knew it was Goodpasture's syndrome because the patient had acute kidney and pulmonary involvement; but what this immunofluorescence pattern represented was a total mystery to clinicians and pathologists of that era. Of course we later learned that this pattern is typical of anti-basement membrane antibody disease. It reflects deposition of an antibody that is reactive with the glomerular basement membrane (GBM). We have heard a lot more about that in several other presentations this morning, and we now 
understand this disease quite well, but at that point in time we had absolutely no clue what this was. As his intern, I was assigned the unpleasant job of telling this patient he was going to die. He was about 26 years old, a young guy, and he was otherwise entirely healthy. In those days you could receive dialysis only if you could get a kidney transplant. The transplant surgeons considered this patient not transplantable because of his pulmonary disease. I was told to get his family together, and sit down and tell them that he had 2-3 weeks left to live before he died of renal failure, which I found to be a very unpleasant task. I went and looked in the literature and I found an old paper by a Professor Goldring at New York University who had given an old cancer chemotherapeutic drug, nitrogen mustard, to a small number of patients with severe glomerulonephritis. Most of them did not have Goodpasture's syndrome but some of them had responded. In those days when we didn't have to deal with human subjects committees, I said to my resident, 'Let's try this; what do we have to lose? If this patient is going to die anyway, let's try it.' We infused this patient with nitrogen mustard; his serum creatinine went up and then went back down again, his clearance improved, his proteinuria went away, and he had a second biopsy that showed resolution of the disease. He actually walked out of the hospital with a near-normal creatinine. I followed him for 2 years after that, and he did extremely well [1]. I found that mystifying. Why did he have this disease? Why did he respond to this very toxic form of therapy? What caused the disease? It was this patient-centered interest that led me into nephrology and Ed's lab in Boston in 1970 and then sparked Kline's interest in joining the group.

So at that point in time, around 1970, we asked: 'How does one get glomerulonephritis?' And here is what we thought: the first thing that happens is you are exposed to 'bad stuff'. We do not know what the bad stuff is: maybe bacteria, maybe a virus, but somehow we are exposed to bad stuff, and we then generate an immune response to defend ourselves. The immune response in each of us is different. Our genetic background conditions it. And the immune response generates antibodies in the blood to attack and remove the foreign material. These antibodies were relatively easy to measure. In 1970, you could measure them by blood tests; you could measure them by their deposition in the kidney as shown in the immunofluorescence with the anti-GBM antibodies deposited in the patient's biopsy. You could see the antibody on the biopsy, so you knew it was there. And those antibodies, as elegantly demonstrated by the work of Frank Dixon and others, caused renal diseases. That is what we knew in 1970.

We also knew that there was a second major component to the immune response, a T-cell component that we could not measure. Nobody knew how to measure whether T cells reacted to, or didn't react to, anything at that point, much less anything about what the T cells did in diseases. Consequently their role in kidney disease, if there was one, was entirely unknown. At that time, Ed Lewis and his colleagues at Harvard's Robert Breck Brigham Hospital used an assay they had developed that first allowed measurement of whether or not a $\mathrm{T}$ lymphocyte was reactive to a particular antigen [2]. They did this measurement in kidney disease and showed that patients who had antibodies to GBM also had T cells that were specifically reactive to GBM. They further had the temerity to suggest that maybe these cells were actually important in the pathogenesis of the disease. That paper was accompanied by an editorial [3], which Ed talked about earlier, a very negative editorial by Dr. Frank Dixon, who was considered the father of immune renal disease. We should not say much critical of this opinion because none of us would be here if it had not been for the work that Dixon and colleagues had done earlier to understand immune renal disease. But he was not very open to this particular concept of a role for $\mathrm{T}$ cells, and wrote the editorial condemning this idea, which basically shut down research in this area for 25 years or so.

Now at that point in time, the world we lived and worked in was becoming very confusing. The Vietnam War was going on, people were wandering around on the moon, everybody was demonstrating against the war, we were at Harvard at the epicenter of this, the women's movement was beginning, and Woodstock happened. With all of this turmoil, Ed, Kline, and I were swept out of Boston and Harvard to the University of Chicago, where we occupied a little lab in a corner of a building. The event I remember most about Kline in Chicago was an episode where I fell on my head, and was then hauled protesting out of my apartment by Dr. Bolton, who took me over to get an X-ray that showed a skull fracture. I don't know whether that episode was a positive event in my career or a negative one. I am sure it influenced my mentality after that! But I owe Kline a great debt of gratitude for not letting me die from the broken head! And then, in 1973, we split up. Ed went to Rush, Kline came here to UVA, and I went to Boston University. And at that point in time we all believed that all glomerulonephritis was due to anti-GBM antibodies or circulating immune 
complexes. That was the dogma, and there was no other paradigm out there.

So I began as a junior faculty member at Boston University without my mentor who was an enormous source of ideas. I have to say that during the time we spent with Ed, we were thinking about things that were 20 years ahead of their time. It is remarkable when you look back on it, the number of new concepts that Ed, Kline and I talked about at that time that subsequently became popular topics of investigation. But in the absence of that environment, and looking for something to do to start my research career, I came up with an idea that would definitely not win any prizes for innovation or originality! The idea was to examine all the cases of crescentic glomerulonephritis at Boston University and count how many patients had anti-GBM disease and how many had immune complex disease, the two mechanisms of glomerulonephritis defined by Dixon and colleagues in the decade before. This was definitely not 'hypothesis-driven' scientific research, but I had to do something to keep myself involved in glomerulonephritis research, and so I did that study. What we found was that occasional patients with crescentic glomerulonephritis had anti-GBM antibody disease and occasional patients had immune complex deposits, but mostly we found patients who seemed to have neither. They had negative immunofluorescence studies. I was a bit bothered by that, wondering what was wrong with me that I couldn't seem to see what everyone else was seeing. I went to the old annual clinical research meetings in Atlantic City, where I ran into my friend Kline Bolton. As we were commiserating, both overworked junior faculty members, I mentioned this observation to him. Kline said, 'You know, we have been studying these patients at the University of Virginia and have found exactly the same thing.' And I thought, 'Maybe we are right!' And so we combined the two groups of patients (Kline had more patients than we had), and published a paper which has been shown several times this morning, describing this entity of crescentic glomerulonephritis without any deposits, which turns out now to be not only a real thing but actually the most common type of crescentic glomerulonephritis [4]. So we were proposing three types of crescentic glomerulonephritis: antiGBM antibody-mediated, immune complex-mediated, and then this new entity without immune deposits, whatever it was. We sent that paper to four or five different journals. It was rejected out of hand by all of them. Our ability to do renal immunopathology was questioned, we were told we didn't know how to do the proper controls, there was something wrong with the antibody, etc., etc.
We finally got it published in a kidney journal, which was a little more sympathetic, but it was a long haul.

So with that background on where he started, let me illustrate for you what Kline has contributed to nephrology. At that point in time we had discovered something apparently new and unexplained by current paradigms. I think we were actually smart enough to know that we had discovered something new; certainly Kline was smart enough to know that we had discovered something new. What I did was basically to cop out: I took the safe path; I went on to study immune complex disease. I spent the rest of my career studying immune complex disease, but it was going back to Frank Dixon, going back to serum sickness, and taking the conventional route. What Kline did, which is to his eternal credit, was exactly the opposite. Kline took what we found and pursued it. Kline actually investigated this new entity we had recognized, developed a hypothesis for what caused it, and did the research to test that hypothesis when it was not a conventional or safe course to follow.

Now, most of us investigating the pathogenesis of a renal disease use animal models. We recreate the disease in animal models, as Ron Falk and others have talked about, and we try to understand it because we can do things in the models that we cannot do in humans. And, of course, what we usually use is either mice or rats. And some of us live with the conviction that these rodents are actually people. We believe, as an article of faith, that these rats and mice are like people, and we are therefore working on patients. Ed does not believe that: Ed gave up the whole laboratory approach and went on to pursue a very successful career working on patients. But some of the rest of us actually believe this. Kline, however, did not do that. Kline went to the chicken to develop an animal model. And when he began to study the chicken, the whole community looked at him aghast. What is wrong with Kline Bolton? Chickens? Do chickens even have kidneys? They don't pee. Why would you study a chicken? But there was a method to the madness. What is unique about the chicken, and why Kline studied the chicken, is that a chicken has a little structure called the Bursa of Fabricius. If you take this thing out, or you give a drug that blocks it, the chicken cannot make antibodies. That means that under those circumstances the only way the chicken can get immunologic kidney disease is through an antibody-independent mechanism. It has to go down the T-cell pathway. Ingenious! So Kline studied chickens. It took another several years after the original observation in man before Kline produced crescentic glomerulonephritis in a chicken, proving that $\mathrm{T}$ cells alone could 
cause nephritis without antibody deposits - like the disease we had found in people [5]. He published a model in which chickens were immunized with basement membrane; they developed (most of them) no antibodies, but they developed severe crescentic glomerulonephritis without the antibodies. In fact, he was able to transfer glomerulonephritis to normal chickens using only these T cells that were sensitized to GBM [6]. And Kline, as was talked about earlier, also remained in the clinical arena and initiated some studies to look at ways of treating this disease which are still in use today [7]. It was about 10-12 years later before Kline's work, which was greeted with less than wild enthusiasm by the world of renal science because it was carried out in chickens, was finally confirmed in a 'real' animal like a rat. Using the Goodpasture antigen, which had by now been identified, another group was able to transfer this disease using sensitized lymphocytes and reproduced crescentic glomerulonephritis without the need of using the chicken [8]. And that confirmation of his earlier work gave Kline an opportunity to respond to the critics [9]. This was really the first time that Dr. Dixon's very skeptical comments had been publicly answered. But they were answered now with hard experimental data that showed that his skepticism was misplaced. It is unfortunate that this was 2002, which is 32 years after 1970, but it finally happened. And of course, Ed Lewis's work looking at macrophage inhibitory factor as a component of crescentic glomerulonephritis was finally confirmed, also a quarter-century later [10], when it was shown that you could prevent crescent formation by blocking the T-cell-derived molecule (macrophage inhibitory factor) that Ed had originally measured to suggest a role for T cells in patients with Goodpasture's syndrome.

So as of 2008, we now understand crescentic glomerulonephritis very differently from 1970 . The antibody part is still much the same, but we can now measure T-cell subsets and T-cell-derived lymphokines; we can assay for cell-mediated immunity to specific antigens. This whole field has evolved enormously, and we know now that this process can indeed cause kidney disease. We know it because Kline did it for the first time in chickens to prove it was possible, and others have since confirmed and extended his work. There is even a possibility that sensitized cells may cause more kidney disease than the antibodies do. So Kline's contributions to nephrology, which have been many and diverse, are most impressively illustrated in my mind by the fact that he has put this entire T-cellmediated aspect of immunologic mechanisms of renal injury on the renal scientific map. Kline was the investiga- tor who swam upstream, jumped in where angels feared to tread, and actually made this thing work. A major, major contribution.

So, are chickens people? Does this happen in real life or only in chickens and sometimes in rats? With respect to the human disease, Ron Falk gets full credit for defining the role of anti-neutrophil cytoplasmic antibody (ANCA) in crescentic glomerulonephritis without immune deposits and has told you something about it in the last talk. Ron and Charley Jennette at North Carolina have spent their careers very productively showing that these antibodies, which were unknown in 1970, in fact do play a significant role in causing the disease, albeit without depositing in glomeruli. But there are still unanswered questions related to this group of diseases. There are still histologic findings like granulomas and giant cells that make you wonder if there isn't something else going on. There are other markers of cell-mediated immunity that are elevated in these patients but not in other kinds of glomerulonephritis as well. There are some clinical observations that make you wonder whether there may not be more to the story than just ANCA. The ANCA levels so far have not predicted the course or the severity of the disease very well. Ron says 5 or $6 \%$, some have said up to $10 \%$, of these patients do not have ANCA. Many patients of course have the antibodies without the disease; and you can put a normal kidney into a patient with ANCA and it seems to do pretty well. Neutrophils are not the most prominent histologic feature of ANCApositive glomerulonephritis. And of course, clinically these patients with crescentic glomerulonephritis without immune deposits look much the same whether or not they have ANCA. So there are reasons to wonder if ANCA explains the whole disease process.

So just as a final overview to illustrate where the Tcell story may fit in, I will attempt to summarize these processes, as we understand them in 2008. We know there are cells sensitized to myeloperoxidase (MPO), the antigen against which the ANCA is directed. Antigenpresenting cells interact with and sensitize lymphocytes. When exposed to antigens to which they have become sensitized, these T lymphocytes make lymphokines like macrophage inhibitory factor, which attract macrophages. The macrophages make cytokines like IL1 and TNF. These cytokines are clearly an important part of this disease. They upregulate the adhesion molecules on the endothelium, and they upregulate ligands for these adhesion molecules on the macrophages. There are, of course, neutrophils involved in this process as well. And the MPO is in the primary granule of the neu- 


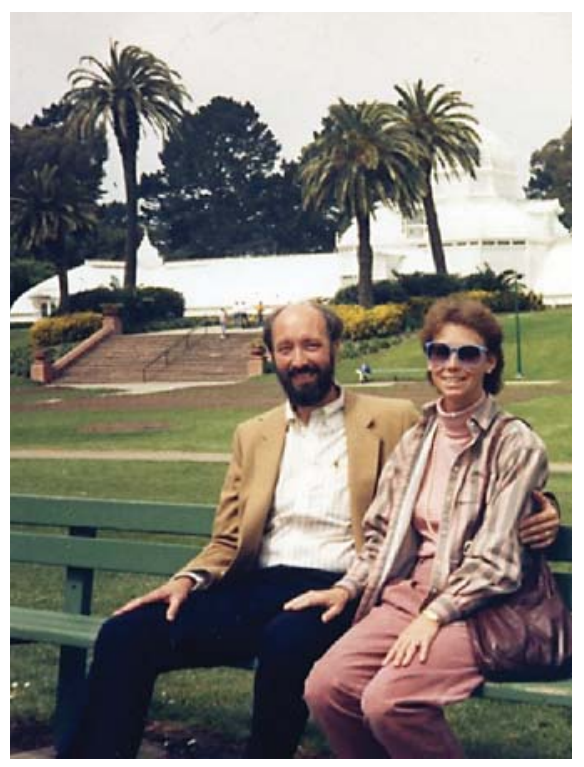

Fig. 3. Kline and Nancy Bolton in San Diego at the American Society of Nephrology Meeting, 1995.

trophil, normally not accessible to outside antibodies, as Ron and his colleagues have elegantly shown. The cytokines upregulate the adhesion molecules for the neutrophil, the neutrophil becomes adherent to the capillary, and the MPO moves to the surface and becomes accessible to circulating ANCA. When this happens, the neutrophilbecomes activated. And it releases things. Among the things it releases is MPO. If you infuse MPO into a kidney, it is a very highly cationic molecule that sticks all over the anionic endothelium of the kidney. We know there are lymphocytes present that are highly reactive to this antigen. But at this point in the schema, we still don't have all of the answers. We don't know for sure exactly what causes the capillary wall damage that occurs at this point. What is the role of the T cell and macrophage? What are the roles of the ANCA and the neutrophils? But all these cells release toxic molecules like proteases and oxidants, and they destroy the underlying capillary basement membrane, and they make a hole. Then into that hole go mononuclear cells, which are delivered to Bowman's space, where the crescents form. They proliferate in Bowman's space; they make additional cytokines, which facilitate their localization by upregulating additional adhesion molecules, and they lead to holes in Bowman's capsule, allowing additional mononuclear cells to enter Bowman's space from the interstitium. These macrophages also do something that neutrophils do not: they make tissue factor. Tissue factor leads to fibrin polymerization; and one then has monocytes, macrophages, interstitial fibroblasts, proliferating parietal epithelial cells, and fibrin - all the elements of the traditional crescent.

That was a simplified overview of where we are in 2008 in understanding the pathogenesis of crescentic glomerulonephritis, the trip on which Kline has led us, from chickens to man over a quarter century. There are still many questions to be answered in this disease. However, the kinds of questions we are asking now are questions that could not have been asked without the work that Kline has done to better define the immunologic pathogenesis of this important group of diseases.

So what are Kline's contributions to nephrology? Certainly, the pathogenesis of crescentic glomerulonephritis, which he has studied at an immunologic level and also at a molecular level with the Goodpasture antigen, stand out in my mind as what his most lasting legacy will likely be. But he has made seminal contributions to many other areas: the treatment of glomerulonephritis including the pulse steroid studies, dialysis, anemia, diabetes, renal biopsy techniques, renal care teams, and transplants. Indeed, there is almost no area in nephrology to which Kline Bolton has not contributed.

So Kline (and Nancy), I salute you, sir (fig. 3). You have had a distinguished and elegant career. And it is certainly not over yet. You continue to earn a level of research funding that most 32-year-old investigators would love to have, and you deserve it. I hope you continue to swim upstream for another couple of decades and put a few more things on the map. It has been an enormous pleasure and source of pride for me to be associated with some of the things you have done. We have had some fun times; we have done some things that turned out to be more interesting than we thought they were at the time we did them. And my own career in nephrology would not have been the same without those experiences, without my good fortune to know you, work with you, share some of these ideas with you, and finally, to come here today and tell these people some of what you have taught us. Thank you so much, Kline, for all of those opportunities. 


\section{References}

1 Couser WG: Goodpasture's syndrome. A response to nitrogen mustard. Am J Med Sci 1974;268:175-180.

$\checkmark 2$ Rocklin R, Lewis E, David J: In-vitro evidence for cellular hypersensitivity to glomerular-basement-membrane antigens in human glomerulonephritis. N Engl J Med 1970;283:497-501.

-3 Dixon FJ: What are sensitized cells doing in glomerulonephritis? N Engl J Med 1970;283: 536-537.

4 Stilmant MM, Bolton WK, Sturgill BC, Couser WG: Crescentic glomerulonephritis without immune deposits: clinicopathologic features. Kidney Int 1979;15:184-195.
5 Bolton WK, Tucker FL, Sturgill BC: New avian model of experimental glomerulonephritis consistent with mediation by cellular immunity. J Clin Invest 1984;73:1263-1276.

6 Bolton WK, Chandra M, Tyson TM, Kirkpatrick PR, Sadovnic MJ, Sturgill BC: Transfer of experimental glomerulonephritis in chickens by mononuclear cells. Kidney Int 1988;34:598-610.

7 Bolton WK, Couser WG: Intravenous pulse methylprednisolone therapy of acute crescentic rapidly progressive glomerulonephritis. Am J Med 1979;6:495-502.
$>8 \mathrm{Wu}$ J, Hicks J, Borillo J, Glass WF II, Lou YH: CD4+ T cells specific to a glomerular basement membrane antigen mediate glomerulonephritis. J Clin Invest 2002;109:517524.

-9 Bolton WK: What sensitized cells just might be doing in glomerulonephritis. J Clin Invest 2002;109:713-714.

10 Yang N, Nikolic-Paterson DJ, Ng YY, Mu W, Metz C, Bacher M, Meinhardt A, Bucala R, Atkins RC, Lan HY: Reversal of established rat crescentic glomerulonephritis by blockade of macrophage migration inhibitory factor (MIF): potential role of MIF in regulating glucocorticoid production. Mol Med 1998;4: 413-424. 